\title{
VIDA IN RUA: DESIGN SOCIAL E GRAFITTI NO JARDIM JERICÓ, CABEDELO - PB
}

\author{
Wilker Cesar Costa de Souza \\ Instituto Federal de Educação, Ciência e Tecnologia da Paraíba \\ wilker.blz@gmail.com \\ Fabrício Vieira de Oliveira \\ Instituto Federal de Educação, Ciência e Tecnologia da Paraíba \\ fabri.v.eira@gmail.com \\ Elizabeth Fernanda Lima Paixão \\ Instituto Federal de Educação, Ciência e Tecnologia da Paraíba \\ paiixaonanda@gmail.com \\ Turla Ângela Alquete De Arreguy Baptista \\ Instituto Federal de Educação, Ciência e Tecnologia da Paraíba \\ turla.alquete@gmail.com \\ Renata Amorim Cadena \\ Instituto Federal de Educação, Ciência e Tecnologia da Paraíba \\ renata.cadena@ifpb.edu.br
}

Resumo: Em meio às diversas dificuldades das comunidades periféricas e em situação de vulnerabilidade, as possibilidades de expressão artística e de fomento à reflexão crítica sobre a realidade a qual estão inseridas é envolta por inúmeras limitações. O enfrentamento das problemáticas vivenciadas na periferia promovem o estímulo à busca por alternativas criativas e as interferências visuais em espaços urbanos têm se tornado cada vez mais frequentes a partir da produção e expressão do Graffiti. Entendido como uma manifestação artística contemporânea, o Graffiti é um das formas de intervenção visual que transforma a estética urbana das cidades e provoca o levantamento de críticas sociais, comportamentais e políticas. A percepção sobre do Design Social associado ao Graffiti como ferramentas de inclusão e de transformação das realidades, agregado ao processo de humanização das comunidades sobressaem como reais alternativas capazes de obter resultados diferenciados na propagação de valores de cidadania. Com a proposta de resgatar o entendimento do Graffiti como manifestação artístico-cultural e buscar promover uma vivência da comunidade com a arte urbana, sua integração com os artistas e seu processo criativo e a transformação visual na valorização do espaço da comunidade, foi desenvolvido o evento de extensão Vida In Rua. Embasado nas métricas do Design Social e da Pedagogia Humanista associadas ao Grafitti, o evento realizado na comunidade do Jardim Jericó, localizada no município de Cabedelo - PB, região conhecida externamente pelo índice de violência, envolvimento dos jovens moradores com o tráfico 
de drogas, promoveu atividades de reflexão e percepção sobre a realidade de vida dos moradores da comunidade e integrado a isso, a execução de oficinas de iniciação ao Graffiti como meio de estimular expressão das vivências e percepções dos participantes. Contou também com a iniciativa de debates e apresentações culturais locais. As iniciativas culminaram com a produção de um painel de Graffiti com artistas convidados e com a confecção de um fanzine informativo e colaborativo, descrevendo e expressando as atividades desenvolvidas no projeto.

Palavras-chave: Design Social, Arte, Graffiti, Cidadania 